\title{
Thoracic duct terminating on the right side associat
with aberrant retro-oesophageal right subclavian artery and truncus bicaroticus
}

\author{
HILEL NATHAN ${ }^{1}$ AND GERSHON GITLIN \\ From the Department of Anatomy, The Hebrew University-Hadassah Medical School, Jerusalem, Israel
}

\begin{abstract}
A case is described showing the following rare combination of anomalies: $(a)$ the thoracic duct terminating on the right side at the junction of the internal jugular and subclavian veins; $(b)$ the right subclavian artery arising as the last branch of the aortic arch, beyond the left subclavian artery, and passing behind the oesophagus on its way to the upper limb; and (c) the right and left common carotid arteries arising by a common stem ('truncus bicaroticus') from the aortic arch. The literature on the subject is reviewed and the embryological basis for the development of these variations is discussed briefly. It is suggested that special attention be directed to the course of the thoracic duct whenever an anomaly of the branches of the aortic arch is observed.
\end{abstract}

Marked variations in the course of the thoracic duct, including its termination at or near the junction of the internal jugular and subclavian veins ${ }^{2}$ on the right side instead of on the left, are well documented in the literature. With the development of modern thoracic surgery, and particularly that of the thoracic duct itself, there has been renewed interest in the anatomy of this structure and recent descriptions of variations in its pathway have appeared (e.g., Griaznova, 1957 ; Kausel, Reeve, Stein, Alley, and Stranahan, 1957 ; Jdanov, 1959 ; Lachapèle, Hughes, and Lagarde, 1964).

It is our purpose in the present report to describe an unusual case in which a thoracic duct terminating at the right venous angle was associated with an aberrant, retro-oesophageal right subclavian artery and a truncus bicaroticus, i.e., right and left common carotid arteries arising by a common stem from the aortic arch. Very few instances of this combination of anomalies have been described.

These findings may be of practical importance in surgery of the thorax and in the interpretation of radiographs of the vessels in the region under consideration. The embryological basis for the development of these variations may also be of interest.

\footnotetext{
1 Present address: Department of Anatomy, University of Tel Aviv Medical School, Tel Hashomer Hospital, Tel Aviv

2 The junction of these two veins will hereafter be refenred to as the 'venous angle', after Swalowsky (1888)
}

\section{OBSERVATIONS AND DESCRIPTION}

The anomalies were found in an adult dissecting-room $\frac{\mathscr{Q}}{\varnothing}$ cadaver. From the top of the aortic arch (Figs 1 and $\varrho$ 4), in front and somewhat to the left of the trachea, $\overrightarrow{\vec{O}}$ there arose a short, broad trunk, the 'truncus 3 bicaroticus' (Swalowsky, 1888), which ascended vertically for approximately $1.5 \mathrm{~cm}$. and divided into the two common carotid arteries: the right, which crossed the anterior surface of the trachea in a direction $\overline{0}$ upwards and to the right, and the left, running upwards and to the left. Both these arteries then con- $x$ tinued into the neck, following their normal course. $\frac{}{3}$ The left subclavian artery arose from the aortic arch immediately to the left of and somewhat behind the $O$ truncus bicaroticus; this vessel then passed upwards and to the left in its normal course towards the left 의 upper limb.

The right subclavian artery originated from the aortic arch $1.5 \mathrm{~cm}$. beyond the left subclavian artery, $N$ immediately opposite the site of attachment of the 9 ligamentum arteriosum (Figs 1-4). It then passed $N$ posteriorly, upwards and to the right between the N oesophagus and the vertebral column (Fig. 2) to reach $\omega$ the inlet of the thorax, whereafter it continued its? course to the upper limb, having the relations of aco normal subclavian artery. This aberrant artery, to- $\bar{\varnothing}$ gether with the right common carotid artery, the? truncus bicaroticus, and part of the aortic arch formed 7 an incomplete vascular ring around the oesophagus and trachea (Fig. 4). An impression was produced on $\overrightarrow{\mathbb{D}}$ the posterior surface of the oesophagus where the $\frac{}{\Phi}$ subclavian artery passed behind it (Fig. 3).

The thoracic duct maintained its normal relations in its course through the inferior mediastinum, i.e., 


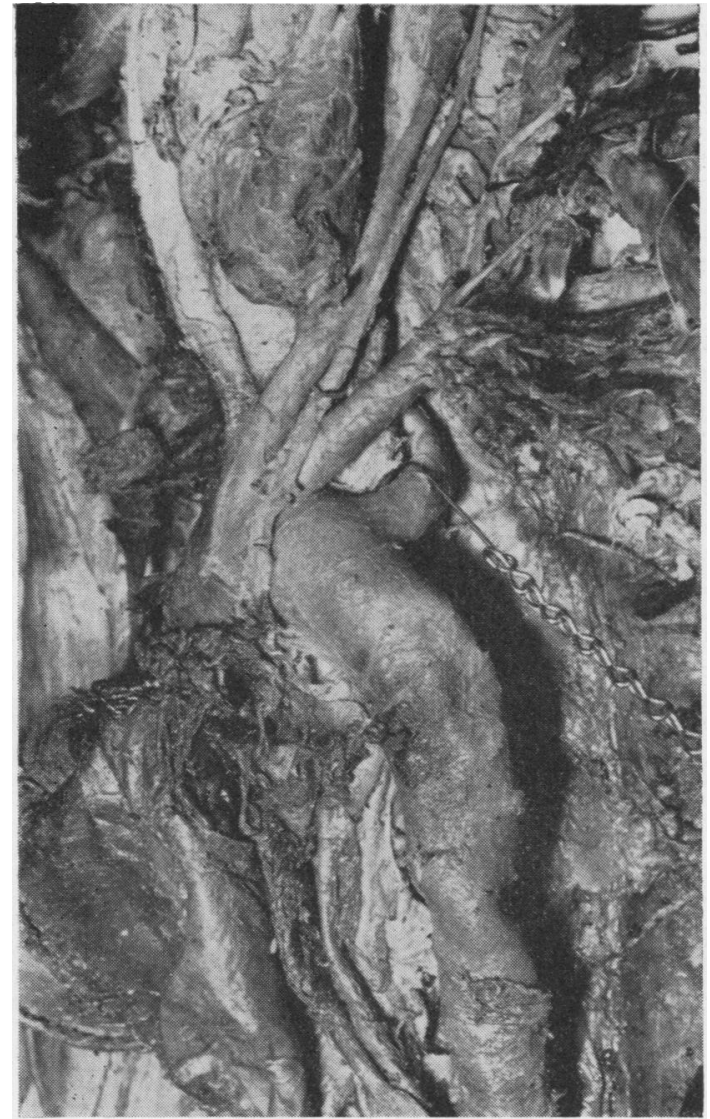

between the azygos vein to the right and the aorta to the left, in front of the vertebral column and behind the oesophagus; but when it entered the superior mediastinum, instead of ascending to the left it departed from its normal course when it met the anomalous right subclavian artery and turned to the right. It accompanied this vessel, ascending along its right (inferior) side until it reached the root of the neck. Here it passed to the front of the artery and entered the right venous angle. While running along the inferior surface of the right subclavian artery the thoracic duct split into two channels which merged again into one common trunk just before entering the venous angle (Fig. 2).

\section{DISCUSSION}

Variations in the origin and course of the branches of the aortic arch are not infrequent and the embryological basis for their development is known. The variation in the course of the right subclavian artery described in the present paper is thought to be a result of the disappearance of

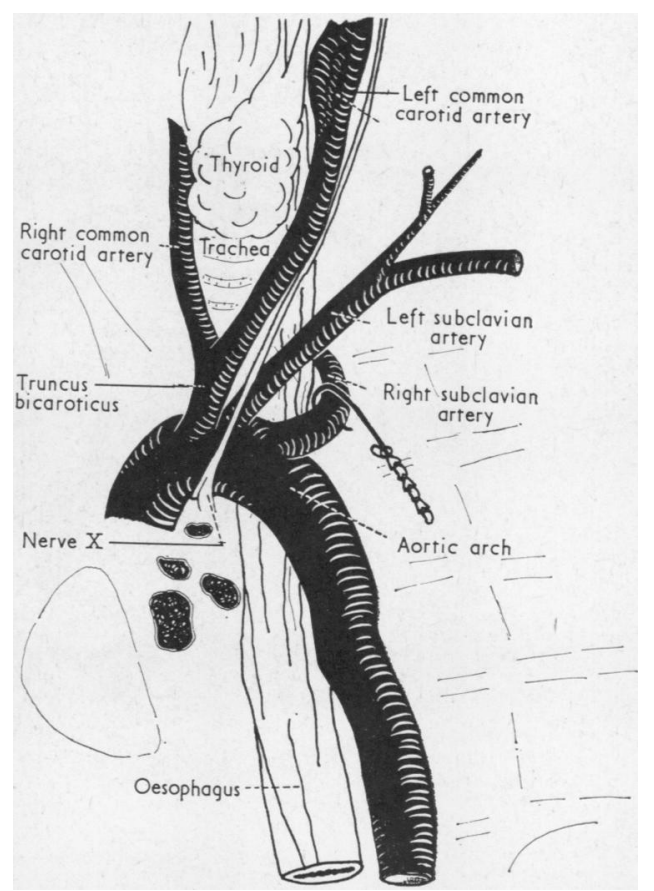

FIG. 1. Photograph (slightly touched up) of the dissected specimen showing the truncus bicaroticus and the aberrant right subclavian artery.

the right fourth aortic arch and the persistence of the eighth segment of the right dorsal aortic root (Stewart, Kincaid, and Edwards, 1964). An aberrant right subclavian artery is a recognized entity; the artery usually runs posterior to the oesophagus but in rare instances may pass between the trachea and the oesophagus (Bankart, Pye-Smith, and Phillips, 1868 ; Videau, 1960). It frequently forms the posterior component of an incomplete vascular ring, the right common carotid artery forming the anterior component, as is seen in our case (Fig. 4). The aberrant right subclavian artery has received much attention because of the pressure which it may exert on the oesophagus, producing disturbances in swallowing (Stewart et al., 1964) ; the indentation of the oesophagus seen in our case (Fig. 3) is similar to that shown by the latter authors and lends support to this view.

As to the prevalence of an aberrant right subclavian artery, according to Stewart et al. (1964) it has been documented that it occurs in one of 


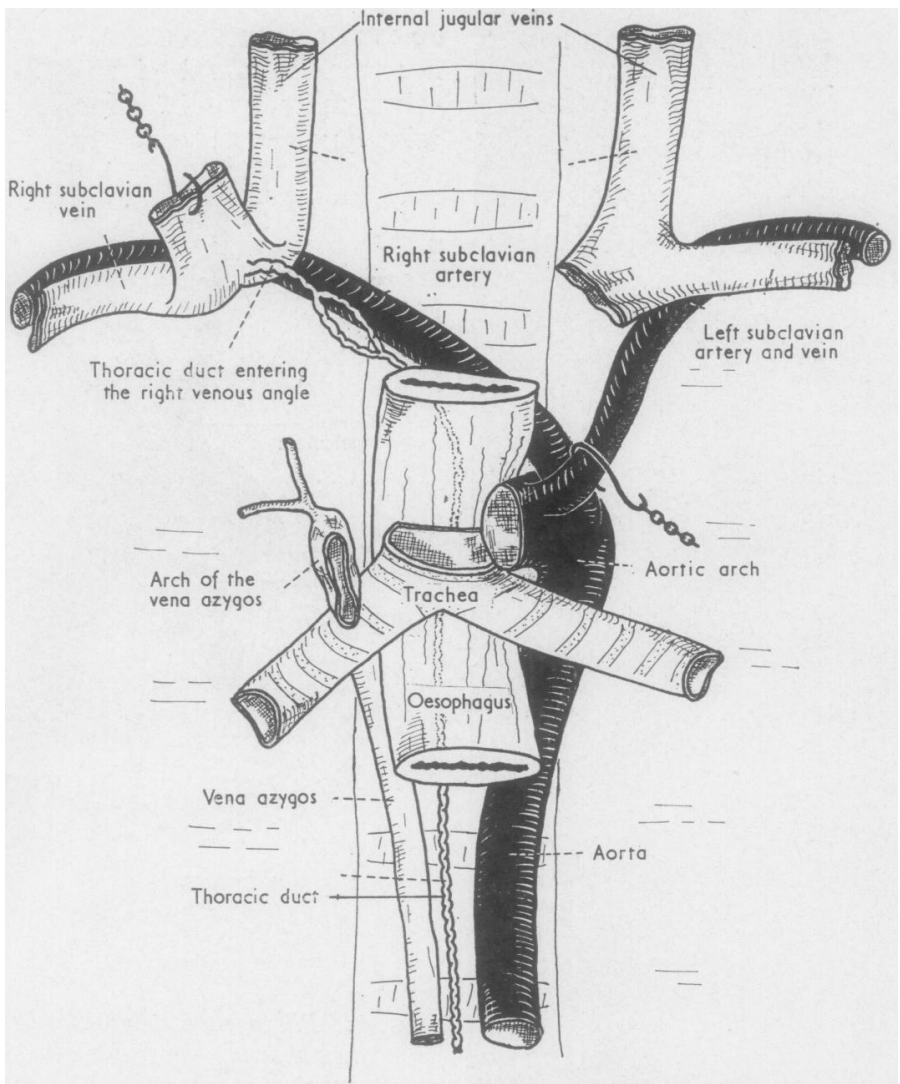

FIG. 2. Semi-schematic representation showing the aberrant right subclavian artery and its relationship to the thoracic duct which terminates at the right venous angle.

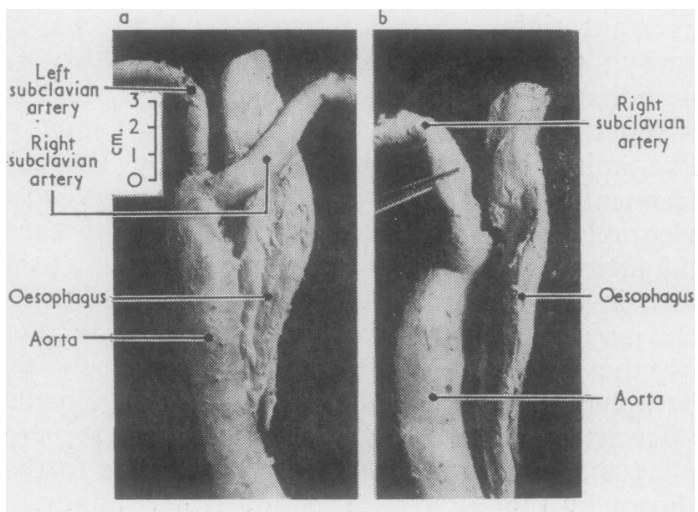

FIG. 3. (a) The aorta and oesophagus viewed from behind; the aberrant right subclavian artery passes posterior to the oesophagus. (b) The same, with the right subclavian artery drawn aside to show the indentation of the oesophagus which it produced. every 200 persons. Grant and Basmajian (1965), however, give the frequency as $1 \%$ and Atanasiu, Oancea, and Panaitescu (1966) found their single specimen in more than 600 dissections.

Truncus bicaroticus-of which Videau (1960) found three cases in 750 dissections-has been less emphasized in the literature. It may be found with a right subclavian artery arising from the aortic arch to the right of the truncus bicaroticus (Videau, 1960) or, as in our case, together with an aberrant right subclavian artery (Bankart et al., 1868; Swalowsky, 1888 ; Calori, 1890 ; Videau, 1960 ; Atanasiu et al., 1966). Klinkhamer (1966) culled 292 cases of aberrant right subclavian artery from the literature, added three of his own, and found that in $86(29 \%)$ the condition was associated with truncus bicaroticus. In his opinion, an aberrant right subclavian artery produces clinical manifestations of dysphagia or-especially in children - of respiratory distress only when it 


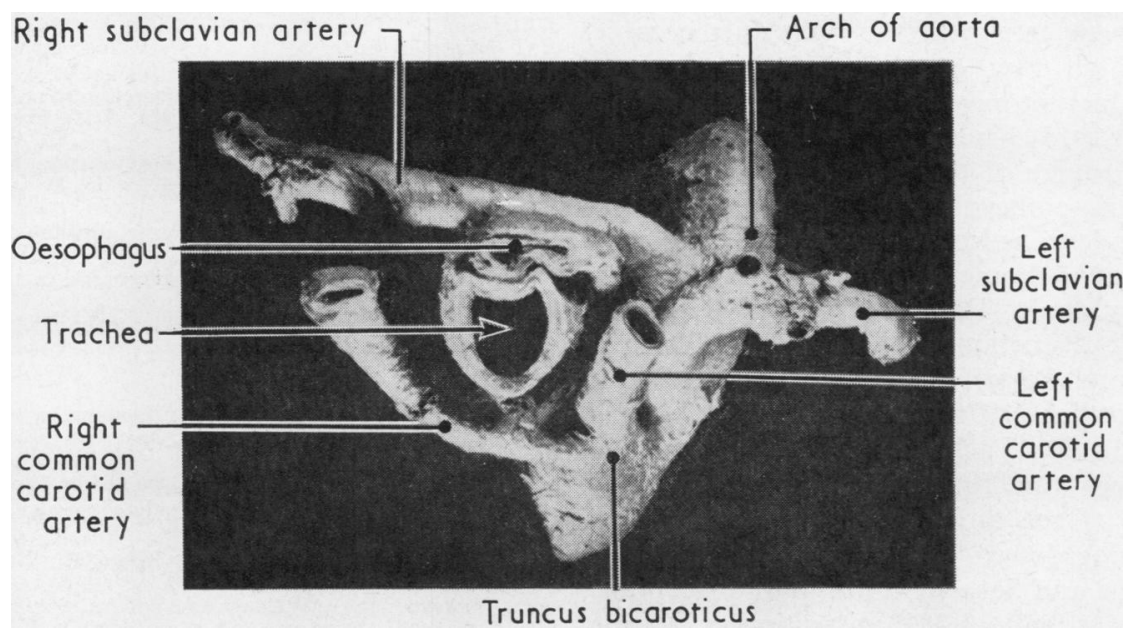

FIG. 4. Incomplete vascular ring around the trachea and oesophagus formed by the right common carotid artery, the truncus bicaroticus, the aortic arch, and the aberrant right subclavian artery.

is associated with truncus bicaroticus or with common carotid arteries arising from the aorta close to one another. The oesophagus and trachea are then hemmed in by the aberrant right subclavian artery dorsally, and the two common carotid arteries ventrally.

Regarding the thoracic duct, many variations in its course are known to occur and a number of classifications have been suggested (e.g., Lane, 1839-47 ; Davis, 1915 ; Rouvière, 1938; Van Pernis, 1949 ; Adachi, 1953 ; Griaznova, 1957 ; Kausel et al., 1957 ; Jdanov, 1959). Lane's (183947) classification may be used conveniently to include the following types of thoracic duct which end partly or wholly at the right venous angle:

I. A double duct, the one terminating at the left, the other at the right venous angle (Davis, 1915 ; Lachapèle et al., 1964) ;

II. A bifurcation of the duct at a higher or lower level, one branch terminating at the left venous angle, the other emptying itself either into the corresponding point on the right side, or joining the right lymphatic duct close to its termination (Thomson, 1884 ; Davis, 1915 ; Rouvière, 1938 ; Butler, 1903 ; Celis and Porter, 1952) ;

III. A single trunk terminating altogether at the right venous angle.

Type III may be classified further (Watson, 1872) into those cases without associated anomalies of the large arteries (Davis, 1915; Minkin, 1925) and those with such abnormalities. The following such arterial aberrations have been described : (a) right-sided aortic arch, without transposition of the heart or other viscera (Thomson, 1862) ;

(b) right vertebral artery arising from the posterior wall of the aorta distal to the ductus arteriosus and passing upwards and to the right, posterior to the oesophagus (Swalowsky, 1888);

(c) right subclavian artery arising as the last branch of the aortic arch and passing upwards and to the right posterior to the oesophagus. The association of this last anomaly with a thoracic duct terminating only at the right venous angle is rare, but nevertheless we have been able to find descriptions of 20 similar cases in the literature (Cruickshank, 1790 ; Fleischman, 1815 ; Todd, 1859 ; Thomson, 1862 ; Walsham, 1880 ; Brown, 1882 ; Brenner, 1883 - three cases ; Thomson, 1884 -three cases; Swalowsky, 1888-seven cases; Calori, 1890). Our own case is similar but has in addition a truncus bicaroticus. Such a trilogy of anomalies, i.e., the thoracic duct ending entirely at the right venous angle, aberrant retrooeosophageal right subclavian artery, and truncus bicaroticus, must be very rare. We have been able to trace only two previously described cases (Swalowsky, 1888 ; Calori, 1890).

The embryological basis for variations in the course of the thoracic duct is well recognized. In the early embryo there exist both right and left thoracic ducts with numerous anastomosing channels between them (Davis, 1915 ; Kampmeier, 1931). The usual or 'textbook' pattern of the adult channel develops in its lower part from the right duct and in its upper part from the left duct. 
Usually, the upper part of the right duct becomes the right lymph duct, but it may become part of a thoracic duct proper, as in the case described here. Davis (1915) has indicated how other variations in the course of the thoracic duct may arise from the basic embryological pattern.

It is difficult to estimate from the literature the prevalence of a thoracic duct terminating at the right venous angle. Davis (1915) found one instance in 22 dissections; Minkin (1925), one in 102 ; Celis and Porter (1952), one in 50; Greenfield and Gottlieb (1956), one in 75 ; Kausel et al. (1957), one in 50 ; Lachapèle et al. (1964), one in 60. However, the following authors, in their descriptions of the thoracic duct, make no mention of having found ducts ending on the right side : Parsons and Sargent (1909)-40 dissections ; Van Pernis (1949)-1,081 dissections; Meade, Head, and Moen (1952)-135 dissections ; Jdanov (1959) - 100 dissections.

As noted, a thoracic duct ending at the right venous angle may or may not be accompanied by anomalies of the large arteries. The extent to which, on the other hand, anomalies in the origin and course of the large arteries are accompanied by anomalies of the thoracic duct is not known; in reports on such arterial abnormalities, the thoracic duct is usually not referred to. However, Calori (1890) noted that cases of retro-oesophageal right subclavian artery are found with the thoracic duct terminating normally on the left side, and Brenner (1883) made the same observation in one of his cases of right-sided aortic arch.

It would thus seem that whatever factor it is that produces either the arterial or the thoracic duct anomaly, it does not of necessity produce both anomalies concomitantly.

On the basis of the findings of the present study we should like to suggest that special attention be directed to the course of the thoracic duct whenever any anomaly in the branches of the aortic arch is observed. This may prove to be of practical importance during thoracic surgery.

We wish to express our sincere thanks to Mrs. E. Salomon for the photographs and to Miss J. Zeldis for the drawings.

\section{REFERENCES}

Adachi, B. (1953). Der Ductus thoracicus der Japaner (Erste Lieferung vom Lymphgefaessystem der Japaner). Quoted by Kubo, R., Shirabe, K., Matsumara, M., Nakagawa, K., and Magata, M.' (1964). J. Otorhinol. Soc. Jap., 67, 1005.
Atanasiu, I., Oancea, T., and Panaitescu, V. (1966). Arteria subclavia $\overrightarrow{\vec{F}}$ dextra als letzter Ast des Aortenbogens. Anat. Anz., 118, 114.

Bankart, J., Pye-Smith, P. H., and Phillips, J. J. (1868). Notes on abnormalities observed in the dissecting room during the winter session 1866-1867 and 1867-1868. Guy's Hosp. Rep., Series 3, O 14. 436 .

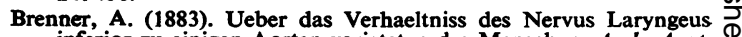
inferior zu einigen Aorten-varieteten des Menschen. Arch. Anat. Physiol., 373.

Brown, J. M. (1882). Note on abnormal distribution of the thoracic ڤึ duct. J. Anat. (Lond.), 16, 301.

Butler, C. S. (1903). On an abnormal thoracic duct. J. med. Res., 10, $\overrightarrow{0}$ 153.

Calori, L. (1890). Sopra un caso d'inversione dei condotti toracici $\overrightarrow{\vec{\omega}}$ accompagnato da inversa origine dell'arteria succlavia destra e $\sigma$ sulla genesi delle due anomalie. Mem. Acad. Sci. Ist. Bologna, $5,89$.

Celis, A., and Porter, J. K. (1952). Lymphatics of the thorax. An anatomic and radiologic study. Acta radiol. (Stockh.), 38, 461. N Cruickshank, W. (1790). Anatomy of the Absorbing Vessels of the $\omega$
Human Body. 2nd ed., London. Quoted by Thomson (1884).

Davis, H. K. (1915). A statistical study of the thoracic duct in man. N Amer. J. Anat., 17, 211.

Fleischman (1815). Leichenöfnungen. Quoted by Thomson (1884).

Grant, J. C. B., and Basmajian, J. V. (1965). Grant's Method of Anatomy. 7th ed. Williams and Wilkins, Baltimore.

Greenfield, J., and Gottlieb, M. I. (1956). Variations in the terminal $飞$ portion of the human thoracic duct. Arch. Surg., 73, 955.

Griaznova, A. V. (1957). On the variations of the thoracic duct in the thorax. Arch. Anat. Histol. Embryol., Moscow, 34, 51. (Russian $\vec{\theta}$ text, English summary.)

Jdanov, D. A. (1959). Anatomie du canal thoracique et des principaux collecteurs lymphatiques du tronc chez l'homme. Acta anat. (Basel), 37, 20.

Kampmeier, O. F. (1931). Ursprung und Entwicklungsgeschichte des Ductus thoracicus nebst Saccus lymphaticus jugularis und Cisterna Chyli beim Menschen. Morph. Jb., 67, 157. Quoted by Rusznyak, I., Földi, M., and Szabo, G. (1957). Physiologie und Pathologie des Lymphkreislaufes. Verlag der ungarischen Akademie der Wissenschaften, Budapest.

Kausel, H. W., Reeve, S. T., Stein, A. A., Alley, R. D., and Stranahan, A. (1957). Anatomic and pathologic studies of the thoracic duct. J. thorac. Surg., 34, 631.

Klinkhamer, A. C. (1966). Aberrant right subclavian artery. Clinical and roentgenological aspects. Amer. J. Roentgenol., 97, 438.

Lachapèle, A. P., Hughes, A., and Lagarde, C. (1964). De l'étude anatomo-radiologique du canal thoracique d'apres 60 opacifications sur l'être humain vivant. J. Radiol. electrol., 45, 1.

Lane, S. (183\%-47). In The Cyclopaedia of Anatomy and Physiology, ed. R. B. Todd. Vol. 3, p. 225 . Longman, Brown and Green, London.

Meade, R. H., Head, J. H., and Moen, C. W. (1952). The management $\times$ of chylothorax. J. thorac. Surg., 19, 709.

Minkin, S. (1925). Zur Frage des rechtsseitigen Verlaufes des Ductus thoracicus. Anat. Anz., 60, 314.

Parsons, F. G., and Sargent, P. W. (1909). On the termination of the thoracic duct. Lancet, 1,1173 .

Rouvière, H. (1938). Anatomy of the Human Lymphatic System. 응 Edwards Brothers, Ann Arbor.

Stewart, J. R., Kincaid, O. W., and Edwards, J. E. (1964). An Atlas of $D$ Vascular Rings and Related Malformations of the Aortic Arch System. Thomas, Springfield.

Swalowsky, J. (1888). Ueber das Verhalten des Ducius thoracicus bei Persistenz der rechten absteigenden Aortenwurzel. Anat. Anz., 3, О 839.

Thomson, Allen (1862). In Turner, W. (1862). On irregularities of the $N$ large blood vessels. Brit. Foreign Med. Chir. Rev., 30, 173.

Thomson, A. (1884). Variations of the thoracic duct associated with $\mathrm{C}$ abnormal arterial distribution. J. Anat. (Lond.), 18, 416.

Todd, R. B., ed. (1859). The Cyclopaedia of Anatomy and Physiology, vol. 5, Longman, Brown and Green, London.

Van Pernis, P. A. (1949). Variations of the thoracic duct. Surgery, 26, 806.

Videau, J. (1960). Anomalies des branches de la crosse aortique. $\stackrel{\text {. }}{?}$ Trav. Lab. Anat. Fac. Méd. d'Alger, 37.

Walsham, W. J. (1880). The thoracic duct ending on the right side in the confluence of the internal jugular and subclavian veins. St Bart. Hosp. Rep., 16, 99.

Watson, M. (1872). Note on the termination of the thoracic duct on the right side. J. Anat. (Lond.), 6, 427. 